\title{
Mammographic Screening of Women Attending a Reference Service Center in Southern Brazil
}

\author{
Tiara Cristina Romeiro Lopes ${ }^{1 *}$, Angela Andreia Franca Gravena ${ }^{1}$, Marcela \\ de Oliveira Demitto ${ }^{2}$, Sheila Cristina Rocha Brischiliari' ${ }^{1}$, Deise Helena Pelloso \\ Borghesan $^{1}$, Catia Millene Dell Agnolo², Maria Dalva de Barros Carvalho ${ }^{3}$, \\ Sandra Marisa Pelloso ${ }^{1}$
}

\begin{abstract}
Background: To investigate the prevalence of and factors associated with performance of annual mammography by women above 40 years of age. Materials and Methods: This cross-sectional retrospective study was conducted at an oncology reference service in Southern Brazil from October 2013 to October 2014 with 525 women aged 40 years or older. Results: The prevalence of annual mammography was $54.1 \%$; annual mammographic screening was performed for women without private medical insurance, who were under hormone replacement therapy and who had used contraception in the past. An association was found between non-performance of breast clinical and self-examination and non-performance of mammographic screening. Conclusions: Use of mammography for breast cancer screening in the public health care setting proved to be accessible; nevertheless, the proportion of screened women was low, and they exhibited poor adherence to the basic measures of care recommended for breast assessment. Thus, control of breast cancer requires implementing actions targeting the population most vulnerable to non-adherence to screening in addition to continuously monitoring and assessing that population to reduce the prevalence of this disease.
\end{abstract}

Keywords: Mammography - screening - breast cancer - early diagnosis - preventive health care - Brazil

Asian Pac J Cancer Prev, 17 (3), 1385-1391

\section{Introduction}

Breast cancer ranks second in global incidence and is considered the most common type of neoplasm among women in both developed and developing countries (Iarc, 2012). According to the National Cancer Institute, 57,120 new cases in Brazil were expected in 2015, corresponding to an estimated risk of 56.09 cases per 100,000 women (Brasil, 2014a). In the Brazilian Southern region, 13,225 deaths by breast cancer were recorded in 2011, while the mortality rate was 13.5 deaths per 100,000 inhabitants. The mortality rate per 100,000 inhabitants increased approximately 71\% from 1990 to 2011 (Brasil, 2014b).

Breast cancer is a progressive disease, which justifies the need for early detection and surgical resection in its early stage to reduce the occurrence of advanced cases of diseaseand its mortality (Tabar et al., 2014). Early detection of breast cancer -before the appearance of a palpable mass - increases the survival and quality of life of women (American College of Obstetricians and Gynecologists Committee on Gynecologic Practice -US, 2011).

Few studies have investigated the actual situation of breast screening programs, being that the offer of free preventive care to women aged 40 years old and older is often rather precariousbecause of barriers and factors that hinder the procurement for this type of care on an annual basis (Schneider et al., 2014; Paiva and Cesse, 2015).

Mammography is the best method to achieve early diagnosis of breast cancer and can lead to a 15.0 to $25.0 \%$ decrease in the mortality of women subjected to mammographic screening (Kobrunner et al., 2011).

Currently, mammographic screening is performed according to the opportunistic model (Tiezzi, 2010), in whichtesting is performed only when women spontaneously seek the screening at healthcare services (Smith, 2011; Miles et al., 2004). For that reason, substantial numbers of women are not screened or do not adhere to the given orientations. Lack of demand and poor adherence are considered problems in this type of screening (Schneider et al., 2014).

Currently, there is no consensus on mammographic screening for women aged 40 to 49 years old (Kettritz, 2010). While the incidence of breast cancer is lower among women within that age range compared to those aged 50 to 69 years (Inca, 2010), the frequencies of dense 
breast tissue and fast-growing tumors are higher among the former. Breast cancer in young women is still poorly understood, and it is believed that it might be a more biologically aggressive disease, with higher frequencies of adverse histopathological characteristics and poorer prognosis compared to older patients (Martins et al., 2013).

Some authors consider that studies with women outside the high-risk age range are necessary, as the peculiarities of each individual population ought to be taken into account when establishing the ideal age for the onset of a mammography-based breast cancer screening program (Silva et al., 2014). Thus, the aim of the present study was to investigate the prevalence of and factors associated with annual performance of mammography among women above 40 years old attended at an oncology reference hospital.

\section{Materials and Methods}

The present cross-sectional retrospective study was performed at an oncology reference service in Southern Brazil with women seen from October 2013 to October 2014. This service performs tests for patients from all of the region's municipalities, including both those privately insured and thoseattended at the Unified Health System (Sistema Unico de Saude - SUS), i.e., the national public health system, which performs a large number of tests.

The study population consisted of all of the women aged 40 years or older who visited the reference service during the study period for annual screening for breast cancer, who were diagnosed or not with breast cancer and whose medical records were complete,totaling 525 women.

To investigate mammographic screening, the participants were first interviewed, and their medical records were then analyzed. The interviews were performed while the participants were waiting for their mammography and routine medical consultation.

The primary outcome variable was self-reported performance of annual mammographic screening by the participants. The secondary measures, or independent variables, were sociodemographic and clinical data: age (categorized in age ranges varying from 40 to $\geq 70$ years old); educational level ( $<8$ or $\geq$ years of formal schooling); marital status (with or without a partner); skin color (white or non-white);paid job (yes or no); medical insurance (yes or no); self-perceived health (categorized as excellent/very good, good/fair and poor/very poor); presence of breast cancer (yes or no); menopausal status (pre- or postmenopausal); past and present hormone replacement therapy (yes or no); past and present use of contraception (yes or no); age at menarche $(<15$ or $\geq 15$ years old); parity (nulliparous, one to three children or $\geq$ four children); breastfeeding (yes or no); and performance of breast clinical and self-examination (yes or no).

In the cases with diagnosed breast cancer, the following clinical-pathological characteristics were assessed: histologic type (ductal or invasive lobular) and clinical stage according to the TNM classification (where $\mathrm{T}$ is the tumor size, ranging from $\mathrm{T} 1$ to $\mathrm{T} 4$, being $\mathrm{T} 1<2 \mathrm{~cm}, \mathrm{~T} 22-5 \mathrm{~cm}, \mathrm{~T} 3>5 \mathrm{~cm}$, and $\mathrm{T} 4$ - tumor of any size with direct extension to the skin and/or chest wall; $\mathrm{N}$ represents the dissemination of disease to the regional

Table 1. Bivariate analysis of performance of annual mammographic screening according to sociodemographicvariables and self-perceived health, Paraná, Brazil, 2015

\begin{tabular}{|c|c|c|c|c|c|}
\hline & \multicolumn{5}{|c|}{ Annual mammographic screening } \\
\hline & Yes & No & OR & $\mathrm{CI}$ & $\mathrm{p}$ \\
\hline & $\mathrm{n}(\%)$ & $\mathrm{n}(\%)$ & & & \\
\hline \multicolumn{6}{|l|}{ Age (years) } \\
\hline 40 to 49 & $79(47.6)$ & $87(52.4)$ & 1.0 & & \\
\hline 50 to 59 & $112(57.1)$ & $84(42.9)$ & 0.68 & $0.44-1.05$ & 0.06 \\
\hline 60 to 69 & $65(61.9)$ & $40(38.1)$ & 0.56 & $0.33-0.95$ & 0.02 \\
\hline$\geq 70$ & $28(48.3)$ & $30(51.7)$ & 0.97 & $0.51-1.85$ & 0.92 \\
\hline \multicolumn{6}{|c|}{ Educational level (years of formal schooling) } \\
\hline$<8$ & $165(53.9)$ & $141(46.1)$ & 1.02 & $0.71-1.46$ & 0.92 \\
\hline$\geq 8$ & $119(54.3)$ & $100(45.7)$ & 1.0 & & \\
\hline \multicolumn{6}{|l|}{ Marital status } \\
\hline With partner & $206(56.4)$ & $159(43.6)$ & 1.0 & & \\
\hline Without partner & $78(48.8)$ & $82(51.3)$ & 1.36 & $0.92-2.01$ & 0.10 \\
\hline \multicolumn{6}{|l|}{ Ethnicity/skin color } \\
\hline White & $154(54.4)$ & $129(45.6)$ & 1.0 & & \\
\hline Non-white & $49(51.6)$ & $46(48.4)$ & 1.12 & $0.69-1.83$ & 0.63 \\
\hline \multicolumn{6}{|l|}{ Paid job } \\
\hline Yes & $107(51.4)$ & $101(48.6)$ & 1.0 & & \\
\hline No & $177(55.8)$ & $140(44.2)$ & 0.84 & $0.58-1.21$ & 0.32 \\
\hline \multicolumn{6}{|c|}{ Private medical insurance } \\
\hline Yes & $147(48.4)$ & $157(51.6)$ & 1.0 & & \\
\hline No & $137(62.0)$ & $84(38.0)$ & 0.57 & $040-0.83$ & 0.001 \\
\hline \multicolumn{6}{|l|}{ Self-perceived health } \\
\hline Excellent/very good & $38(56.7)$ & $29(43.3)$ & 1.0 & & \\
\hline Good/fair & $222(53.4)$ & $194(46.6)$ & 1.15 & $0.66-1.99$ & 0.60 \\
\hline Poor/very poor & $24(57.1)$ & $18(42.9)$ & 1.98 & $0.42-2.30$ & 0.96 \\
\hline
\end{tabular}


lymph nodes: NO - no regional lymph node metastasis, $\mathrm{N} 1$-metastasis to movable ipsilateral axillary lymph node(s), N2 - metastasis in fixed ipsilateral axillary lymph node(s) or clinically apparent metastasis to ipsilateral internal mammary lymph node(s) in the absence of clinical evidence of axillary lymph node metastasis, N3 -metastasis in ipsilateralinfraclavicular lymph node(s) with or without axillary lymph node(s) involvement, or clinically apparent in ipsilateral internal mammary lymph node(s) in the presence of clinical evidence of axillary lymph node metastasis, or metastasis in ipsilateral supraclavicular lymph node(s), with or without axillary or internal mammary lymph node involvement; and $\mathrm{M}$ indicates presence or not of distant metastasis: M0 - no distant metastasis, M1 - with distant metastasis, MX: presence of distant metastasis could not be assessed) (Brasil, 2004). The various combinations of TNM categories (letters and numbers) determine the clinical stage of disease, which varies from I to IV in most cases; the following stages were found in the present study: (I; IIA; IIB; IIIA; IIIB; IV) - I: early local invasion; II: the primary tumor is limited or there is minimal extension to the regional lymph nodes; III: extensive local tumor or extensive affection of the regional lymph nodes; and IV: locally advanced tumor or presence of metastasis (Brasil, 2011). The estrogen and progesterone receptors (positive or negative) and the presence or absence of the triplenegative subtype (TNBC) (yes or no) were also assessed.

For better understanding, the information was tabulated by means of descriptive (means and standard deviations) and crude analyses. In the bivariate analysis of annual performance of mammography and associated factors, crude analysis was employed through calculations ofodds ratios (ORs) and chi-square testresults using Epi Info 3.5.1.softwareat a 5\% significance level and a 95\% confidence interval (CI).

All of the participants signed an informed consent form approved by the permanent committee of ethics in research involving human beings, State University of Maringa (Universidade Estadual de Maringa - UEM),ruling no. 353,649 .

Table 2. Bivariate Analysis of Annual Mammographic Screening According to Presence of Breast Cancer, Risk Factors, Breast Self-exam and Clinical Examination, Parana, Brazil, 2015

\begin{tabular}{|c|c|c|c|c|c|c|}
\hline & & \multicolumn{5}{|c|}{ Annual mammographic screening } \\
\hline & & Yes & No & OR & CI & $\mathrm{p}$ \\
\hline & & $\mathrm{n}(\%)$ & $\mathrm{n}(\%)$ & & & \\
\hline \multicolumn{7}{|l|}{ Breast cancer } \\
\hline Yes & & $44(45.7)$ & $51(54.3)$ & 1.47 & $0.92-2.35$ & 0.08 \\
\hline No & & $241(55.9)$ & $190(44.1)$ & 1.0 & & \\
\hline \multicolumn{7}{|l|}{ Menopause } \\
\hline Premenopause & & $70(48.6)$ & $74(51.4)$ & 1.0 & & \\
\hline Postmenopause & & $214(56.2)$ & $167(43.8)$ & 0.74 & $0.49-1.10$ & 0.12 \\
\hline \multicolumn{7}{|c|}{ Past hormone replacement therapy } \\
\hline Yes & & $59(70.2)$ & $25(29.8)$ & 0.44 & $0.26-0.74$ & 0.001 \\
\hline No & & $225(51.0)$ & $216(49.0)$ & 1.0 & & \\
\hline \multicolumn{7}{|c|}{ Current hormone replacement therapy } \\
\hline Yes & & $18(60.0)$ & $12(40.0)$ & 0.77 & $0.34-1.73$ & 0.50 \\
\hline No & & $266(53.7)$ & $229(46.3)$ & 1.0 & & \\
\hline \multicolumn{7}{|l|}{ Past use of OC } \\
\hline Yes & & $207(59.0)$ & $144(41.0)$ & 0.55 & $0.38-0.81$ & 0.001 \\
\hline No & & $77(44.3)$ & $97(55.7)$ & 1.0 & & \\
\hline \multicolumn{7}{|c|}{ Age at menarche (years) } \\
\hline$<15$ & & $264(54.2)$ & $223(45.8)$ & 1.13 & $0.54-2.38$ & 0.73 \\
\hline$\geq 15$ & & $20(57.1)$ & $15(42.9)$ & 1.0 & & \\
\hline \multicolumn{7}{|l|}{ Parity } \\
\hline Nulliparous & & $23(59.0)$ & $16(41.0)$ & 1.43 & $0.73-2.85$ & 0.27 \\
\hline 1 to 3 & & $170(52.6)$ & $153(47.4)$ & 1.14 & $0.77-1.69$ & 0.50 \\
\hline$\geq 4$ & & $91(58.8)$ & $72(44.2)$ & 1.0 & & \\
\hline \multicolumn{7}{|c|}{ Breastfeeding (months) } \\
\hline$<12$ & & $78(55.7)$ & $62(44.3)$ & 0.97 & $0.63-1.47$ & 0.86 \\
\hline$\geq 12$ & & $169(54.9)$ & $139(45.1)$ & 1.0 & & \\
\hline Did not breastfeed & & $37(48.1)$ & $40(51.9)$ & 1.31 & $0.77-2.23$ & 0.28 \\
\hline \multicolumn{7}{|c|}{ Family history of breast cancer } \\
\hline Yes & & $43(59.7)$ & $29(40.3)$ & 0.77 & $0.45-1.31$ & 0.30 \\
\hline No & & $241(53.2)$ & $212(46.8)$ & 1.0 & & \\
\hline \multicolumn{7}{|c|}{ Clinical examination } \\
\hline Yes & & $195(63.1)$ & $114(36.9)$ & 1.0 & & \\
\hline No & & $89(41.4)$ & $126(58.6)$ & 2.42 & $1.67-3.52$ & $<0.001$ \\
\hline \multicolumn{7}{|l|}{ Self-exam } \\
\hline Yes & & $170(58.2)$ & $122(41.8)$ & 1.0 & & \\
\hline No & 114 (49.4) & $117(50.6)$ & 1.43 & $1.01-2.06$ & 0.04 & \\
\hline
\end{tabular}


Table 3. Bivariate analysis of annual mammographic screening according to clinical-pathological characteristics, Paraná, Brazil, 2015

\begin{tabular}{|c|c|c|c|c|c|}
\hline & \multicolumn{5}{|c|}{ Annual mammographic screening } \\
\hline & \multirow{2}{*}{$\begin{array}{c}\text { Yes } \\
\mathrm{n}(\%)\end{array}$} & \multirow{2}{*}{$\frac{\text { No }}{\mathrm{n}(\%)}$} & \multirow[t]{2}{*}{ OR } & \multirow[t]{2}{*}{$\mathrm{CI}$} & \multirow[t]{2}{*}{$\mathrm{p}$} \\
\hline & & & & & \\
\hline \multicolumn{6}{|l|}{ Tumor stage } \\
\hline I & $2(100.0)$ & - & 1 & & \\
\hline IIa and IIb & $24(51.1)$ & $23(48.9)$ & NA & & \\
\hline IIIa and IIIb & $6(27.3)$ & $16(72.7)$ & NA & & \\
\hline IV & $1(33.3)$ & $2(66.7)$ & NA & & \\
\hline \multicolumn{6}{|l|}{ Histologic type } \\
\hline Invasive ductal & $39(46.4)$ & 45 (53.6) & 1 & & \\
\hline Invasive lobular & $2(33.3)$ & $4(66.7)$ & 1.73 & $0.25-14.52$ & 0.68 \\
\hline \multicolumn{6}{|l|}{ TNM } \\
\hline \multicolumn{6}{|l|}{$\mathrm{T}$} \\
\hline $\mathrm{T} 1$ & $11(68.8)$ & $5(31.3)$ & 1 & & \\
\hline $\mathrm{T} 2$ & $22(40.0)$ & $33(60.0)$ & 3.3 & $0.89-12.84$ & 0.08 \\
\hline $\mathrm{T} 3$ & $4(40.0)$ & $6(60.0)$ & 3.3 & $0.49-24.54$ & 0.22 \\
\hline $\mathrm{T} 4$ & $1(14.3)$ & $6(85.7)$ & 13.2 & $0.99-38.28$ & 0.02 \\
\hline \multicolumn{6}{|l|}{$\mathrm{N}$} \\
\hline No & $18(48.6)$ & $19(51.4)$ & 1 & & \\
\hline $\mathrm{N} 1$ & $11(42.3)$ & $15(57.7)$ & 1.29 & $0.42-4.02$ & 0.61 \\
\hline N2 & $6(31.6)$ & 13 (68.4) & 2.05 & $0.56-7.74$ & 0.22 \\
\hline N3 & $1(33.3)$ & $2(66.7)$ & 1.89 & $0.12-5.11$ & 1 \\
\hline \multicolumn{6}{|l|}{ M } \\
\hline M0 & $12(36.4)$ & $21(63.6)$ & 1 & & \\
\hline M1 & $2(50.0)$ & $2(50.0)$ & 0.57 & $0.05-6.74$ & 0.62 \\
\hline MX & $19(44.2)$ & $24(55.8)$ & 0.72 & $0.26-2.02$ & 0.49 \\
\hline \multicolumn{6}{|l|}{ Estrogen receptor } \\
\hline Positive & $27(40.9)$ & $39(59.1)$ & 1 & & \\
\hline Negative & $10(62.5)$ & $6(37.5)$ & 0.42 & $0.12-1.44$ & 0.11 \\
\hline \multicolumn{6}{|c|}{ Progesterone receptor } \\
\hline Positive & $23(39.7)$ & $35(60.3)$ & 1 & & \\
\hline Negative & $13(59.1)$ & $9(40.9)$ & 0.45 & $0.15-1.38$ & 0.11 \\
\hline \multicolumn{6}{|l|}{ TNBC } \\
\hline Yes & $4(57.1)$ & $3(42.9)$ & 0.59 & $0.09-3.52$ & 0.69 \\
\hline No & $25(43.9)$ & $32(56.1)$ & 1 & & \\
\hline
\end{tabular}

Angela Andréia França Gravena ${ }^{1}$

\section{Results}

The present study used data from 525 women who performed their annual screening visits at the aforementioned hospital. Their average age was $55.25 \pm$ 9.99 years old. The women aged 60 to 69 years old $(61.9 \%)$ performed mammographic screenings on an annual basis; the adherence to the test was higher among the participants without private health insurance (62\%; see Table 1).

Approximately $70.2 \%$ of the women who reported having performed hormone replacement therapy and $59.0 \%$ of those who reported having used contraception in the past performed the annual screening test. Nonperformance of breast clinical and self-examination was associated with non-performance of mammographic screening (Table 2). The results of the analysis performed relative to the diagnosed/confirmed cases of breast cancer only. There was an association between non-performance of annual screening and larger tumor size (Table 3).

\section{Discussion}

Mammography is the first-choice test for the detection of breast cancer because of its impacts on reductions of disease morbidity and mortality. However, screening programs meet several difficulties in Brazil as a result of poor infrastructure, high costs and low population adherence. Thus, accurate knowledge of the factors associated with performance of mammography might provide grounds for the implementation of measures likely to enhance women's adherence to the test and the implementation of public health policies, which justifies the performance of the present study.

The prevalence of annual mammography among the study participants was $54.1 \%$. Among women aged 50 to 69 years, the expected coverage of mammographic screening is $70 \%$ of the targeted population within the public health setting (Brasil, 2014c). Performance of annual mammography was associated with lack of private medical insurance, i.e., those who performed the test through the public health services.A study conducted in Southern Brazil investigated the number of mammography devices both available and in use in public health services in the state of Parana; the results showed that the number was sufficient for the targetpopulation (Lopes et al., 2015).

In the Northern region, where the municipality of the present study is located, there is one mammography device 
in use per 6,951 women, while the ratio recommended by the Brazilian Health Ministry is one per 240,000 inhabitants. However, in addition to the number of devices, other factors are also crucial for the actual coverage, such as the geographic distribution of the devices, the number and proficiency of professionals to both request and perform the test, the population's distribution and the supply of health services (Lopes et al., 2015).

A study based on a population survey in Southern Brazil found a lower prevalence of performance of mammography (43.5\%), with a higher prevalence among women with private medical insurance $(51.6 \%)$ compared to those without (28.5\%) (Schneider et al., 2014).

Adherence to annual mammography was highest in the group of women aged 60 to 69 years. A prospective randomized study on mammographic screening found a reduction in breast cancer mortality, especially amongwomen older than 50 years (Euhus et al., 2015). In the United States, mammographic screening programs recommend screening every two years for women aged 50 to 74 years (US Preventive Services, 2009). In Brazil, women should perform mammography every two years from age 50 to 69 years, except for those in high-risk groups (Brasil, 2014a; Marques et al., 2015). With such a regimen, the adherence of the targetpopulation to the test/screening and the prevalence of performance of mammography should improve. Younger women are recommended to undergo breast clinical examination starting at age 40 years old (Brasil, 2014a).

The controversies surrounding breast cancer ought to be taken into consideration. According to some authors, mammographic screening of older women leads to a substantial rate of overdiagnosis, with consequent unnecessary treatment and increasedtreatment-related mortality (Kalager et al., 2010). Other authors, while asserting and believing that mammographic screening reduces mortality and that mammography is the ideal imaging technique for screening for breast cancer, put its efficacy into question on the grounds that the rates of both false-positive and false-negative results still need to be reduced (Chetlen et al., 2015).

The authors of a study that assessed divergences among several opinions on the effects of mammographic screening on breast cancer mortality and overdiagnosis found that when researchers estimate the decrease in breast cancer mortality based on data from the same period and using the same screening method, there is a substantial reductionin mortality (Duffy et al., 2013).

Mammographic screening also exhibited significance among women who performed hormone replacement therapy. Additionally, women who had used contraception in the past exhibited greater adherence to mammography. Breast cancer is caused by multiple factors, including the influence of hormones. One study sought to investigate the possible relationship between the use of hormonal contraception and hormone replacement therapy among women diagnosed with the most common types of breast cancer, taking age at diagnosis into consideration. However, the results were inconclusive because the influence of hormones on tumors is difficult to establish
(Predna et al., 2015).

A study that investigated risk factor associations for breast cancer by method of detection found that among postmenopausal women, estrogen-progestin hormone use was predominantly associated with risk of cliniciandetected breast cancer but not with mammographydetected breast cancer $(\mathrm{OR}=1.49 ; 95 \% \mathrm{CI}: 1.29-1.72)$ (Sprague et al., 2015).

Another study conducted in Pakistan found that the use of an oral contraception was protective against breast cancer; the relationship to the use of hormone replacement therapywas controversial (Sufian et al., 2015).

A study on opportunistic mammographic screening performed in Malaysia found that women with previous mammograms were more likelythan those without previous mammograms to have performed hormone replacement therapy ( $<<0.001)$ (Hassan et al., 2015).

In addition to mammography, some of the screening methods recommended to reduce breast cancer morbidity and mortality are breast self-exam and clinical examination (Ersin and Bahar, 2013; Yilmaz et al., 2013).

In the present study, we found that women who did not perform breast clinical and self-examination also failed to perform annual mammographic screening. A study on screening for breast cancer conducted in Saudi Arabia found that women who had performed breast clinical examination were more prone to perform mammography (El Bcheraoui et al., 2015).

A cross-sectional study conducted in Klang Valley, Malaysia, found that breastself-examination was not frequently performed among the local women (AkhtariZavare et al., 2015).

More than $90 \%$ of breast cancer cases might be cured provided they are diagnosed early and treated in an efficacious manner. A study conducted in Iran with 12,660 women aged 35 to 64 years of age found that breast selfand clinical examinationssignificantly increasedbreast cancer detection in early stages $(<3)$; those techniques proved to be efficacious and widely available, were low in cost and could be applied in the community (Hassan et al., 2015).

The breast cancer diagnosis rate by clinical examination is similar to the rates of diagnosis via several imaging techniques; nevertheless, the examination is disappearing from clinical practice (Euhus et al., 2015). According to some authors, targeted education should be implemented to improve early breast cancer detection (Akhtari-Zavare et al., 2015).

Among women with confirmed diagnosis of breast cancer, non-performance of annual screening was associated with larger tumor size.

Breast cancer is diagnosed in advanced stages in countries with limited resources. In Morocco, breast cancer is the most frequent neoplasm among women (36.1\%); screening methods are likely to reduce the proportion of late diagnosis cases (Fakir et al., 2015).

In Brazil, approximately $60 \%$ of breast cancer cases are diagnosed in stages III and IV, characterized by invasion of the regional lymph nodes and metastasis, respectively. These data are indicative of lack of either prevention or access to diagnosis; those cases might be diagnosed when 
in stages I and II, which would increase the survival of the affected population (De Moura et al., 2013).

One study analyzed the use of mammography for detection of breast cancer relative to the disease stage at diagnosis. The prevalence of screening had a positive correlation with diagnosis in the stage of in situ disease (correlation: $0.66 ; \mathrm{p}<0.001)$ and a negative correlation $(-0.66 ; p<0.001)$ with the percentage of cases diagnosed in advanced stages (Haukka et al., 2011).

Another factor related to tumor size and prognosis that ought to be taken into consideration is the frequency of screening mammograms. A study conducted with 15,440 women found that premenopausal women diagnosed with breast cancer were more prone to have tumors with poorer prognoses when screening had been performed every two years instead of annually. Those women exhibited a greater proportion of tumors in stage IIB or more advanced, tumors with size over $15 \mathrm{~mm}$ and any other characteristic indicative of poorer prognosis compared to those women who had performed annual screenings (Miglioretti et al., 2015). Another study found that women with family historiesof breast cancer who were subjected to annual screening had greater odds of having tumors with size $\leq$ $20 \mathrm{~mm}$ at diagnosis compared to those women screened every two years and women without family histories of disease (Randall et al., 2008).

Screening for breast cancer holds prominent places in public health, health care delivery, policy and women's health care decisions (Onega et al., 2014). Screening programs should be implemented all across the country by both the government and the private sector and should include adequate recommendations concerning breast cancer and educatingwomen on the importance of detecting the earliest signs and symptoms of disease. Special attention should be paid to the importance of immediate medical care, the benefits of early diagnosis and the prognosis and lethality of disease when diagnosed in an advanced stage (Memon et al., 2013).

Several factors are causing changes in the approach to breast cancer screening, including advanced imaging technologies, measurements of health system performance, concern with "excess diagnosis" and improvements in the understanding of risk. A refined conceptual model for breast cancer screening is needed to align women's risk and preferences with screening regimens (Onega et al., 2014).

The present study found that the percentage of women who adhered to mammography performed according to the recommended criteria was low and was higher among those aged 60 to 69 years. Based on these results,we suggest that actions to motivate women to perform breast self- and clinical examinations should be implemented, as women who did not perform these examinations were more vulnerable to alack of annual mammographic screenings that would contribute to early disease diagnosis and reduced mortality. A limitation of the present study is the factthat data collection was performed by means of interviews, as the consistency of self-reported information might have caused bias, with consequent over- and underestimations of the reality.

\section{References}

Akhtari-Zavare M, Juni MH, Ismail IZ, et al (2015). Health Beliefs and Breast Self-Examination among Undergraduate Female Students in Public Universities in Klang Valley, Malaysia. Asian Pac J Cancer Prev, 16, 4019-23.

American College of Obstetricians and Gynecologists Committee on Gynecologic Practice (US) (2011). ACOG practice bulletin No. 122: breast cancer screening. Obstet Gynecol, 118, 372-82.

Brasil (2004). Ministerio da saude. controle do cancer de mama. documento de consenso. brasilia (DF): ministerio da saude.

Brasil (2011). Ministerio da saude. manual de bases tecnicas da oncologia - sia/sus - sistema de informacoes ambulatoriais. secretaria de atencao a saude/ departamento de regulacao, avaliacao e controle/coordenacao geral de sistemas de informacao.

Brasil (2014)a. Instituto nacional do cancer jose alencar gomes da silva. coordenacao geral de prevencao e vigilancia. estimativa 2014: incidencia de cancer no brasil. rio de janeiro: INCA, Brasil.

Brasil (2014)b. Ministerio da Saude. Departamento de Informatica do SUS (DATASUS). Informacoes de Saude.

Brasil (2014)c. Ministerio da saude. instituto nacional do cancer jose alencar gomes da silva. coordenacao geral de prevencao e vigilancia. divisao de deteccao precoce e apoio a organizacao de rede. ficha tecnica de indicadores relativos as acoes de controle do cancer de mama. rio de janeiro: INCA, Brasil.

Chetlen A, Mack J, Chan T (2015). Breast cancer screening controversies: who, when, why, and how? Clinical imaging, 1-4.

De Moura NAV, Castro VB, De Oliveira Costa MA (2014). Epidemiological profile of women with breast cancer treated in hospital philanthropic reference/Perfil epidemiologico de mulheres com cancer de mama tratadas em hospital filantropico de referencia. Revista de Enfermagem da UFPI, 2, 35-41.

Duffy SW, Chen TH, Smith RA, et al (2013). Real and artificial controversies in breast cancer screening. Breast Cancer Management, 2, 519-528.

El Bcheraoui C, Basulaiman M, Wilson S, et al (2015). Breast Cancer Screening in Saudi Arabia: Free but Almost No Takers. PLoS One, 10, 119051.

Ersin F, Bahar Z (2013). Barriers and facilitating factors perceived in Turkish women's behaviors towards early cervical cancer detection: A qualitative approach. Asian Pac J Cancer Prev, 14, 4977-82.

Euhus D, Di Carlo PA, Khouri NF (2015). Breast Cancer Screening. Surg Clin North Am, 95, 991-1011.

Hassan LM, Mahmoud N, Miller AB, et al (2015). Evaluation of effect of self-examination and physical examination on breast cancer. Breast, 24, 487-90.

Haukka J, Byrnes G, Boniol M, et al (2011). Trends in Breast Cancer Mortality in Sweden before and after Implementation of Mammography Screening. PLoS ONE, 6, 22422.

Heywang-Kobrunner SH, Hacker A, Sedlacek S (2011). Advantages and disadvantages of mammography screening. Breast Care (Basel), 6, 199-207.

Iarc. Agencia Internacional de Pesquisas com Cancer (2012). GLOBOCAN-Cancer Incidence and Mortality Worldwide. Available at: http://globocan.iarc.fr

kalager M, Zelen M, Langmark F, et al (2010). Effect of screening mammography on breast-cancer mortality in Norway. New England Journal of Medicine, 363, 1203-10.

Kettritz U (2010). Screening of breast cancer - an eternal discussion revisited? Breast Care (Basel), 5, 119-20. 
Marques CA, Figueiredo EN, Gutierrez MG (2015). Validacao de instrumento para identificar acoes de rastreamento e deteccao de neoplasia de mama. Acta Paulista de Enfermagem, 28, 183-89.

Martins CA, Guimaraes RM, Silva RL, et al (2013). Evolucao da mortalidade por cancer de mama em mulheres jovens: desafios para uma Politica de Atencao Oncologica. Rev Bras Cancerol, 59, 341-49.

Memon ZA, Shaikh AN, Rizwan S, et al (2013). Reasons for patient's delay in diagnosis of breast carcinoma in Pakistan. Asian Pac J Cancer Prev, 14, 7409-14.

Miles A, Cockburn J, Smith RA, et al (2004). A perspective from countries using organized screening programs. Cancer, 101, 1201-13.

Ministerio da Saude (2010). Instituto Nacional de Cancer. SISMAMA - Informacao para o avanco das acoes de controle do cancer de mama no Brasil.

Onega T, Beaber EF, Spraque BL, et al (2014). Breast Cancer Screening in an Era of Personalized Regimens: A Conceptual Model and National Cancer Institute Initiative for RiskBased and Preference-Based Approaches at a Population Level. Cancer, 120, 2955-64.

Paiva CJK, Cesse EAP (2015). Aspectos relacionados ao atraso no diagnostico e tratamento do cancer de mama em uma unidade hospitalar de pernambuco. Revista Brasileira de Cancerologia, 61, 23-30.

Predna L, Habanova M, Slavikova E, et al (2015). Hormonal contraceptives and hormone replacement therapy as a possible risk factor for breast cancer. Rocz Panstw Zakl Hig, 66, 269-74.

Romeiro-Lopes TC, Gravena AAF, Dell Agnolo CM, et al (2015). Cobertura estimada de mamografia no estado do Parana. Ciencia Saude, 8, 48-53.

Sufian SN, Masroor I, Mirza W, et al (2015). Evaluation of common risk factors related to breast carcinoma in females: a hospital based study in Karachi, Pakistan. Asian Pac J Cancer Prev, 16, 6347-52.

Fakir SE, Najdi A, Khazraji YC, et al (2015). Breast Cancer Screening in Morocco: Performance Indicators During Two Years of an Organized Programme. Asian Pac J Cancer Prev, 16, 6285-8.

Schneider IJ, Giehl MW, Boing AF, et al (2014). Rastreamento mamografico do cancer de mama no Sul do Brasil e fatores associados: estudo de base populacional. Cad. Saude Publica, 30, 1987-97.

Silva FX, Katz L, Souza ASR, et al (2014). Mammography in asymptomatic women aged 40-49 years. Rev Saude Publica [online], 48, 931-39.

Smith RA (2011). International programs for the detection of breast cancer. Salud Publica Mex, 53, 394-404.

Sprague BL, Gangnon RE, Hampton JM, et al (2015). Variation in breast cancer-risk factor associations by method of detection: results from a series of case-control studies. $\mathrm{Am}$ J Epidemiol, 181, 956-69.

Tabar L, Dean PB, Chen TH-H, et al (2014). The impact of mammography screening on the diagnosis and management of early phase breast cancer. In: Francescatti D, Silverstein M, eds. Selected Topics in Breast Surgery. Berlin: Springer; 2014.

Tiezzi DG (2010). Cancer de mama: um futuro desafio para o sistema de saude nos paises em desenvolvimento. Rev Bras Ginecol Obstet, 32, 257-59.

US Preventive Services Task Force (2009). Screening for breast cancer: US Preventive Services Task Force recommendation statement. Ann Int Med, 151, 716-26.

Yilmaz D, Bebis H, Ortabag T (2012). Determining the awareness of and compliance with breast cancer screening among Turkish residential women. Asian Pac J Cancer Prev, 14, 3281-88. 